\title{
ASPECTOS HISTÓRICOS DA EDUCAÇÃO INFANTIL NO BRASIL
}

José Ricardo Silva, Fabiana Lohani de Sousa

Universidade Estadual Paulista - UNESP, Faculdade de Ciências e Tecnologias, Presidente Prudente, SP. E-mail: ricardo.unesp@hotmail.com.

\section{RESUMO}

Este trabalho tem como objetivo contribuir com a compreensão da história da Educação Infantil brasileira. Pela pesquisa bibliográfica, apresentam-se dados históricos sobre as primeiras instituições educacionais destinadas às crianças, o processo de profissionalização da função educativa e políticas públicas. Tais apontamentos demonstram a relação entre as instituições infantis com o assistencialismo social, a precariedade na formação dos educadores responsáveis e a falta de intervenção política mesmo com a publicação de documentos norteadores e mandatários pelo governo federal. Atualmente, percebemos que resquícios históricos ainda estão presentes nas concepções e práticas pedagógicas. Ainda há muito a ser feito pelas instituições de educação infantil no Brasil.

Palavras Chave: História; Assistencialismo; Gênero; Cuidar e educar; Educação Infantil.

\section{ABSTRACT}

This paper aims to contribute to understanding the history of the Brazilian Childhood Education. It presents historical data on the first educational institutions for children, the process of professionalization of educational purpose and public policy. Therefore, it was used as a methodology to bibliographic search. These notes show the relationship between children's institutions with the social welfare, poor in teacher training and the lack of responsible political intervention even with the publication of guiding documents and assigns the federal government. Currently, we realize that historical remnants are still present in the conceptions and teaching practices. Much remains to be done by the institutions of child education in Brazil.

Keywords: History; Welfare; Gender; Care and education; Early Childhood Education. 


\section{INTRODUÇÃO}

De acordo com Kuhlmann Jr. (2007), existe uma grande diversidade de opiniões acerca dos temas e das causas que teriam influenciado o surgimento das primeiras instituições destinadas às crianças brasileiras. Segundo este autor, o surgimento das instituições pré-escolares - creches, escolas maternais e jardins de infância - corresponde ao resultado da interação entre o tempo histórico e suas influências com o período de elaboração de uma proposta educacional com características predominantemente assistencialistas.

Haja vista que o objetivo em creches ou asilos, assim chamados em épocas remotas, possuía certo cunho educacional destinado à população mais pobre, esses espaços se configuraram, então, como instituições destinadas a uma educação específica para esse setor social da população, dirigida à submissão não só das famílias, mas também das crianças. Uma educação mais moral do que intelectual, o que assegurava sua baixa posição na sociedade sem condições de pensarem em suas realidades. Essa educação pobre para pobres, oferecida nestas instituições, portanto, não resguardaria o direito da criança e da família ao pleno desenvolvimento social.

A Constituição Federal de 1988 (BRASIL, 1988), destaca a Educação Infantil em creches e pré-escolas como um direito da criança, dever do Estado e da família. No artigo 208, estipula a efetivação do dever do Estado com a educação na garantia de atendimento em creche e pré escola para crianças de 0 a 6 anos de idade. O "Estatuto da Criança e do Adolescente" (ECA), Lei no 8.069, promulgado em 13 de julho de 1990 (BRASIL, 1990), garante atendimento em creches e pré-escola às crianças de 0 a 6 anos de idade. A "Lei de Diretrizes e Bases da Educação Nacional" (LDB), Lei no 9.394 (BRASIL, 1996), constitui a Educação Infantil, como etapa da Educação Básica.

Estas e outras conquistas são resultados de anos de lutas, estudos e pesquisas, que garantiram a legitimidade educacional da Educação Infantil. Todavia, a variação histórica sobre o surgimento das primeiras "instituições" que objetivavam o cuidado e a guarda de crianças, a questão do gênero feminino no desempenho desta função e o assistencialismo, foram e são marcas históricas que passaram por diversas modificações com decorrer do tempo. Embora, esta temática tenha se tornado tema recorrente de pesquisas, podemos observar, ainda hoje, resquícios históricos que influenciam práticas pedagógicas e políticas públicas. Sob esta preocupação, o objetivo deste trabalho é expor fatos históricos que influenciaram direta e indiretamente no surgimento das instituições de Educação Infantil no Brasil. Acreditamos que tematizar a história da Educação Infantil brasileira ainda é pertinente pois, possibilita a reflexão acerca das atuais perspectivas presentes nas políticas públicas e tendências pedagógicas.

\section{METODOLOGIA}

Para o desenvolvimento dessa pesquisa, foi utilizada a pesquisa bibliográfica. Esta metodologia de pesquisa caracteriza-se como

(...) o estudo sistematizado desenvolvido com base em material publicado em livros, revistas, jornais, redes eletrônicas, isto é, material acessível ao público em geral. Fornece instrumental analítico para qualquer outro tipo de pesquisa, mas também pode esgotar-se em si mesma (MORESI, 2003, p. 10).

Com o auxílio deste tipo de pesquisa, foram resgatados conhecimentos acumulados para fundamentarmos nossa discussão teórica acerca do tema. Destacam-se entre os autores historiadores da educação, Moysés Kuhlmann Junior (2007) e Tizuko Morchida Kishimoto (2002a).

\section{RESULTADOS}

A história do surgimento da Educação Infantil no Brasil não foi diferente da história dos modelos educacionais europeus. A educação destinada à criança foi historicamente construída, 
por um lado, para as crianças burguesas e, por outro, para salvar as crianças que não poderiam ser cuidadas pelas próprias mães (LEITE FILHO, 2008).

Kishimoto (2002a) ao abordar a realidade da infância no Brasil colonial e dos diversos modelos institucionais como creches, asilos e internatos constituídos para atender crianças que apresentavam carências diversas, pontua que a história do Jardim de Infância, no Brasil, inicia-se em 1875, ocasião em que Joaquim Menezes Vieira e sua esposa, D. Carlota, inauguram uma instituição com o objetivo de atender crianças entre 5 e 7 anos. Segundo a Gazeta de Notícias, esta instituição foi identificada como Jardim de Infância, já que se justificava como necessária para o desenvolvimento intelectual ou fase preparatória para o primário, mas, por vezes, foi confundida com asilo infantil, caracterizada como instituição de caridade. De acordo com a autora, esta confusão terminológica deve-se à falta de discernimento sobre os objetivos das referidas instituições, firmada por veículos de comunicação e em discursos políticos da época.

Kuhlmann Jr. (2007) destaca, ainda, que, por volta de 1899, ocorreram dois fatos que permitem considerar este ano como marco inicial do surgimento das primeiras propostas de instituições pré-escolares no Brasil - a fundação do Instituto de Proteção e Assistência à Infância no Rio de Janeiro e a inauguração da creche da Companhia de Fiação e Tecidos Corcovado, também no Rio de Janeiro. Entretanto, ainda segundo este autor, anteriormente ao referido ano, ocorreram algumas manifestações que contribuíram para a fundação destas instituições. Em 1879, é lançado, no Rio, o jornal $A$ Mãi de Família, direcionado às mães burguesas. Seu redator era um médico especialista em moléstias de crianças. Suas primeiras publicações faziam referências à creche.

Em 1883, houve a tentativa, em vão, de se realizar um congresso sobre instrução, que, por fim, resultou na Exposição Pedagógica do Rio de Janeiro e em publicação de textos elaborados para o congresso. Em uma análise destes textos, Kuhlmann Jr. (2007) constata a intenção de seus autores de discutir a educação pré-escolar e os interesses privados. A utilização do termo pedagógico era uma estratégia mercadológica para atrair famílias com alto poder aquisitivo para os Jardins de Infância, diferentemente dos asilos e creches direcionados às crianças pobres. A esta altura, os kindergartens de Froebel ainda eram instituições fora do alcance das classes populares, na Áustria e na Alemanha.

Com a aproximação do fim do Império (1889), o grande descaso com a educação pública recaía, também, sobre a criação e a expansão de Jardins de Infância. Com o início da República (1889 a 1930), o quadro também não se modifica muito. Kishimoto (2002a) chama a atenção para os protagonistas da época que não consideravam função do Estado "desmamar crianças" com "diversões pedagógicas". Para eles, a criança constituía-se, apenas, como um ser que necessitava de cuidados maternos e, desprender tanto dinheiro para construir instituições para educá-la seria um desperdício financeiro já que este seria o papel da mãe. Já para crianças abandonadas ou órfãs eram resguardadas a atenção das organizações humanitárias e as intervenções do Estado no sentido do cuidado médico, nutritivo e higiênico, caracterizando, historicamente, o atendimento voltado às crianças pobres como um atendimento assistencialista.

Foi neste período, entretanto, que houve a criação do primeiro Jardim de Infância estadual, decorrente de um projeto político dos burgueses do café. Seu redator, Francisco Rangel, propagandista e fundador do jornal $O$ Estado de S. Paulo, entende a educação como instrumento de mudança social. Em 1890, pensando no papel dos professores nesta mudança social, elabora um projeto de reforma da Escola Normal e cria as escolas-modelos.

Contudo, é na publicação do Decreto de Gabriel Prestes Bernardinho de Campos e Alfredo Pujol, em 2 de março de 1896, que o Jardim de Infância ganha legitimidade. Porém, sua função é, ainda, a de preparar as crianças para o próximo nível escolar como, por exemplo, no anexo da Escola Caetano de Campos; e serviria, também, como espaço para estágios de formação docente. Mesmo com as críticas de Menezes Vieira em 1883 sobre a inadequação de algumas indicações de 
Fröebel, como por exemplo, o abuso das abstrações científicas para a criança, suas práticas evidenciam os dons e as ocupações similares as experiências americanas, trazidas para o Brasil por protestantes.

Durante os primeiros anos da República, apenas em São Paulo havia duas instituições, o anexo da Escola Normal de Caetano de Campos e o Duque de Caxias. No início da década de 1930, as pré-escolas que surgiriam teriam um modelo escolarizante. Assim, de acordo com Kishimoto (2002a), o "longo período de marginalização da Educação Infantil", constitui-se com a grande diversidade de instituições que surgiram com o objetivo de cuidar e, posteriormente, ao longo do tempo, também educar crianças.

O nascimento das instituições voltadas à criança no Brasil é influenciado por processos de industrialização do país e do mundo. Influenciados pela industrialização, urbanização e atendimento às mães trabalhadoras. A expansão deste tipo de instituição foi possibilitada pelos diversos mantenedores: a igreja, as empresas filantrópicas e órgãos de assistência social. Este tipo de instituição caracterizava-se, desde já, como um "mal necessário", destinado a cuidar de crianças enquanto suas mães estivessem nas fábricas, trabalhando. As personagens - que no cenário social atuam com o cuidado e a educação de crianças em seus lares - seriam as mesmas a atuarem nos asilos e nas instituições de Educação Infantil criadas no início do século, com este mesmo objetivo de cuidar e educar, ou seja, funções historicamente construídas, baseadas na versão masculina do trabalho da mulher (OLIVEIRA, et al. 2005).

Ainda de acordo com Sayão (2010), essa identificação gerada quanto ao gênero, favoreceu, também, a má formação das mulheres designadas a este ofício. Já que, inicialmente, para a função assistencialista das primeiras instituições destinadas ao objetivo de resguardar, proteger crianças pobres ou cuidar de filhos de operárias, não era exigido qualquer tipo de formação. Esta função da mulher trabalhadora nestas instituições, identificada com seus afazeres domésticos, trilharia um caminho de décadas, pelo qual cada vez mais o gênero feminino se afirmaria como o mais preparado e específico para exercer o cargo.

Para Arce (2001), a ambiguidade entre o que é ciência e o que é doméstico, no cotidiano de instituições de Educação Infantil é reforçada na utilização entre termos como "professora" e "tia". O que configura a escassa definição da imagem e do trabalho da profissional que atua nessa área. Com isso, a má qualidade do atendimento nas instituições de Educação Infantil apresenta uma relação muito estreita com os estereótipos criados através dos tempos para esta função.

É somente no final do século XIX que há menções sobre creche como um espaço institucional complementar ou substituto da família. O intuito dessa instituição era o de atender crianças pobres e evitar que estas ficassem nas ruas, em troca de abrigo, comida e roupa. As creches surgem, então, como substitutas da Roda dos Expostos, existentes no país desde o século XVII e, mais tarde, o Jardim de Infância de caráter privado que, diferentemente da creche, atendia crianças abastadas usando o termo "pedagógico", pois, além de cuidar, educavam as crianças que atendiam. De acordo com Kishimoto (1999 apud MONTENEGRO, 2001), é durante esta época que se instaura a falsa dicotomia entre cuidar e educar.

\section{DISCUSSÃO}

Um aspecto a destacar é que muitas outras creches surgiram no país como instituições emergenciais de caráter assistencialista que evidenciavam a insuficiência de recursos e a má qualidade do atendimento das crianças pobres. Arce (2001) destaca que esta utilização de espaços ociosos e/ou cedidos por outros tipos de instituições e o trabalho voluntário, caracterizando ainda mais a não profissionalização desta função, são fatores que marcaram profundamente a Educação Infantil brasileira nas décadas de 70 e 80 . 0 atendimento de baixa qualidade, destinado às crianças das camadas menos favorecidas ficou ainda mais evidente com o vínculo destas instituições com 
as Secretarias da Assistência Social e não à Educação. Consolidando o preconceito e o atendimento compensatório, já que contribuiria para que as crianças não ficassem nas ruas.

Santos (2005) ressalta que esta realidade viria a se (re) configurar com a promulgação da Constituição Brasileira em 1988, que formalizou legalmente o direito à creche aos filhos de pais trabalhadores. Já a Lei de Diretrizes e Bases da Educação Nacional (LDB 93/94) transferiu a Educação Infantil da Secretaria de Assistência para a Secretaria de Educação entendendo-a como etapa da Educação Básica. No decorrer dos tempos, o cuidado passaria a ser secundarizado, pois o educar seria o foco das instituições voltadas para a infância, e a creche seria uma extensão das finalidades da família.

Kishimoto (2002a) e Haddad (2006) opõem-se ao modelo escolarizante quando este ultrapassa a mediação de conhecimento entre educador e criança, pois a adoção deste modelo em creche e pré-escola demonstra-se inadequada para esta faixa etária. A educação deve, portanto, superar esta tendência que prevalece até hoje nas escolas infantis. Por isso, na atuação do dia a dia das profissionais responsáveis pelas crianças, o cuidar e o educar precisam ser pontos muito claros em suas ações. Lembrando que esses dois pontos são complementares em uma instituição de Educação Infantil e um não deve sobrepor o outro. O que a observação dessas instituições deixa claro é que o ato de cuidar e o de educar correspondem a ações que ocorrem em conjunto, mesmo que inconscientemente por parte das responsáveis, e que são tarefas indivisíveis. Quando se trata da educação da criança, não existe cuidado sem educação e não existe educação sem cuidados.

Corroboramos com Cerisara (1999) e Haddad (2006), ao apontarem que esta dicotomia é falsa. A relação entre o cuidar e o educar sempre esteve presente no cotidiano das instituições de resguardo e proteção da criança. Quem educa está cuidando e quem cuida está educando, seja por meio de práticas educativas dirigidas (momentos individuais ou coletivos dos atendidos, hora do banho ou da alimentação), seja por meio de maus tratos, exclusão, violência física ou verbal. A necessidade está na qualidade desta relação de cuidado e educação da criança e como está sendo realizado este atendimento. Uma qualidade que apenas será possível quando superarmos marcas históricas do assistencialismo, da escolarização e da formação dos/das profissionais que atuam com crianças pequenas.

Em seu ponto de vista, Haddad (2006) expõe que o perfil profissional desejado para esta qualidade no atendimento não deve ser de um modelo escolar cujo principal objetivo seja o ensino de disciplinas. A autora também salienta que o atendimento na Educação Infantil não pode pautar-se no modelo de mãe-substituta que apenas cuida das crianças enquanto seus pais estão fora.

\section{CONSIDERAÇÕES FINAIS}

Em síntese, procuramos estruturar uma faixa temporal de modo a explicitar as nuances históricas que marcam até os dias atuais as instituições de Educação Infantil. Nesta linha do tempo, evidenciou-se a necessidade de se criar estabelecimentos destinados, inicialmente, ao amparo de crianças e, posteriormente à sua educação.

Este amparo das crianças era realizado por um trabalho feminino, devido, particularmente, a uma questão de gênero. As personagens - que no cenário social atuam com o cuidado e a educação de crianças em seus lares - seriam as mesmas a atuarem nos asilos e nas instituições de Educação Infantil criadas no início do século XX, com este mesmo objetivo de cuidar e educar, ou seja, funções historicamente construídas, baseadas na versão masculina do trabalho da mulher. Estes e outros fatos históricos contribuíram para que fossem lançados documentos federais que, através de propostas e orientações, norteariam o trabalho em instituições de Educação Infantil. De um modo geral, tais documentos apregoam a concepção de que a infância se constitui em uma fase crucial para a formação plena da criança, a qual precisa, sobretudo, de cuidados e de 
intervenções valiosas e diversificadas que propiciem o seu desenvolvimento social, afetivo, moral, estético, motor e cognitivo.

Mesmo de forma desigual por conta dos diferentes contextos do país, os marcos legais destacados neste tópico estão em andamento no atual cenário brasileiro. Observa-se, porém, que ainda persistem alguns modelos de atendimentos resistentes às mudanças definidas pela legislação. Os autores citados ao longo do texto chamam a nossa atenção para a situação precária das creches que, quando comparadas às pré-escolas, são as mais marginalizadas, seja em relação à estrutura física, à formação de professores, e à valorização dos cuidados físicos (higiene e alimentação). Já nas pré-escolas, as professoras prendem-se em propostas exclusivamente escolarizantes. Por isso, a Educação Infantil ainda necessita de muitos avanços.

\section{REFERÊNCIAS}

ARCE, A. Compre o kit neoliberal para a educação infantil e ganhe grátis os dez passos para se tornar um professor reflexivo. Educação e Sociedade, Campinas, v. 22, n. 74, p. 251-283, 2001, https://doi.org/10.1590/S0101-73302001000100014.

BRASIL. Constituição (1988). Constituição da República Federativa do Brasil. Brasília: Senado Federal, 1988.

. Ministério da Educação e Cultura. Lei de Diretrizes e Bases da Educação. Brasília: MEC, 1996. Disponível em: <http://portal.mec.gov.br/arquivos/pdf/ldb.pdf>. Acesso em: 17 dez. 2011.

. Presidência da República. Casa Civil. Subchefia para Assuntos Jurídicos. Lei n. 8069, de 13 de julho de 1990. Dispõe sobre o Estatuto da Criança e do Adolescente e dá outras providências. Disponível em: <http://www.planalto.gov.br/ccivil_03/leis/L8069.htm>. Acesso em: 17 dez. 2011.

CERISARA, A. B. Educar e cuidar: por onde anda a educação infantil? Perspectiva, Florianópolis, v. 17, n. especial, p. 11-21, jul./dez. 1999. Disponível em: <http://www.periodicos.ufsc.br/index.php/perspectiva/article/viewFile/10539/10082>. Acesso em: 05. jun. 2010.

HADDAD, I. Políticas integradas de educação e cuidado infantil: desafios, armadilhas e possibilidades. Cadernos de Pesquisa, São Paulo, v. 36, n. 129, p. 519-546, set./dez. 2006, https://doi.org/10.1590/S0100-15742006000300002.

KISHIMOTO, T. M. Educação e cuidado com a criança de zero a seis anos: problemas e perspectivas. In: MENIN, A. M. C.; GOMES, A. A.; LEITE, Y. U. (Orgs.) Políticas públicas: diretrizes e necessidades da educação básica. Presidente Prudente: Cromograf, 2002a. p. 45-67.

KUHLMANN JR., M. Infância e Educação Infantil: uma abordagem histórica. 4. ed. Porto Alegre: Mediação, 2007.

LEITE FILHO, A. G. Políticas para a educação da infância no Brasil nos anos 1950/1960. 2008. Tese Pontifícia Universidade Católica do Rio de Janeiro, Rio de Janeiro, 2008.

MONTENEGRO T. O cuidado e a formação moral na educação infantil. São Paulo: Educ, 2001.

MORESI, E. Metodologia de pesquisa. Série didática, UCB, 2003. 108 p. Disponível em:

<http://www.inf.ufes.br/ falbo/files/MetodologiaPesquisa-Moresi 2003.pdf>. Acesso em: 15 maio 2012. 
OLIVEIRA Z. de M. et al. Creches: crianças, faz de conta \& Cia. 13. ed. Petrópolis: Vozes, 2005.

ROSEMBERG, F. Creches domiciliares - argumentos ou falácias - 1986.

SANTOS, M. O. V. A identidade da profissional de educação infantil. In: GUIMARÃES, C. M. (Org.). Perspectivas para educação infantil. Araraquara: Junqueria \& Marin, 2005. p. 87-101.

SAYÃO, D. T. Não basta ser mulher... não basta gostar de crianças... "Cuidado/educação" como princípio indissociável na Educação Infantil. Educação, Santa Maria, v. 35, n. 1, p. 69-84, jan./abr. 2010. Disponível em: <http://www.ufsm.br/revistaeducacao. Acessado em: 01 de maio de 2010. 